Антон Геннадиевич Ялоза

преподаватель Днепропетровской

академии музыки имени М. Глинки

odma_n@ukr.net

\title{
«БОЛЬШАЯ УВЕРТЮРА» М. ДЖУЛИАНИ В ПРЕДСТАВИТЕЛЬСТВЕ КЛАССИКИ ГИТАРНОГО ИСКУССТВА ИТАЛЬЯНСКОГО БИДЕРМАЙЕРА
}

Цель исследования - выделить органику гитарного академического существа в контексте бидермайера, определивщего исторически классику гитарного обнаружения в профессиональной музыке. Научная новизна - впервые в Украине гитарное наследие М. Джулиани стало в центре исследовательской проблематики стиля итальянского бидермайера. Методологической основой работы является интонационный подход в музыковедении школы Б. Асафьева в Украине, с выделением в нем герменевтического, стилево-компаративного и культурологического методов. Выводы позволяют осознать высокие достоинства «Большой увертюра» М. Джулиани в представительстве классики гитарного искусства итальянского бидермайера. Последнее в условиях современного постмодерна обнаруживает противонаправленные тенденции проромантической театрализации-оркестрализации звучания инструментасоло и пробидермайеровского салонного символизма, что закономерно вписывается в полиметодологические раскладки творчества сегодняинего дня.

Ключевые слова: М. Джулиани, Grande Ouverture, гитарное искусство, бидермайер, итальянский бидермайер.

Anton Yaloza, lecturer of epy DnipropetrovskM/Glinka music academy

«Grande Ouverture «of M. Giuliani in representation of classics of guitar art of the Italian Biedermeier

Purpose of the article consist in allocating of organic properties of a guitar academic being in the context of the Biedermeier which has defined historically classics of guitar detection in professional music. Scientific novelty. For the first time in Ukraine the guitar heritage of M. Giuliani became in the center of a research perspective of style of the Italian Biedermeier. A methodological basis of work is intonational approach in musicology of school of B. Asafyev in Ukraine, with allocation in him hermeneutical, style comparative and culturological methods. Conclusions allow to realize high advantages «Grande Ouverture» M. Giuliani in representation of classics of guitar art of the Italian Biedermeier. The last in the conditions of a modern postmodern finds opposing tendencies of pro-romantic theatrical-orchestral of sounding of the tool - solo and pro-Bie-

(c) Ялоза А. Г., 2017 
dermeier saloon symbolism that naturally fits into polymethodological apportions of creativity of today.

Keywords: M. Giuliani, Grande Ouverture, guitar art, Biedermeier, Italian Biedermeier.

Антон Геннадійович Ялоза, викладач Дніпропетровської академії музики імені М. Глінки

«Велика увертюра» М. Джуліані в представництві класики гітарного мистещтва италійського бідермайера

Мета дослідження - виділити органіку гітарної академічної суттності у контексті бідермайера, який історично визначив класику гітарного виявлення в професійній музиці. Наукова новизна - вперше в Україні гітарна спадщина М. Джуліані виявилася в иентрі дослідницької проблематики стилю італійського бідермайера. Методологічною основою роботи є інтонаційний підхід в музикознавстві школи Б. Асаф 'єва в Україні, з виділенням у ньому герменевтичного, стильово-компаративного і культурологічного методів. Висновки дозволяють усвідомити високі достоїнства «Великої увертюри» М. Джуліані в представництві класики гітарного мистецтва італійського бідермайера. Останне в умовах сучасного постмодерну виявляе протинаправлені тенденції проромантичної театралізації-оркестралізації звучання інструменту-соло і пробідермайєрівського салонного символізму, що закономірно вписується в поліметодологічні розкладки творчості сьогоденності.

Ключові слова: М. Джуліані, Grande Oиvеrture, гітарне мистецтво, бідермайер, італійський бідермайер.

Актуальность избранной темы определяется значимостью гитарного исполнительства в современном академическом и популярном искусстве, которое в условиях неосимволизма поставангарда [6, 99-134] определило ренессанс бидермайера и раннего романтизма, отмеченных выраженными протосимволистскими стилевыми показателями (см.творчество У. Блейка, Ф. Гойи, К. Фридриха, Ф. Рунге, В. Гюго $[5,35-42])$.

Современное состояние музыковедческих разработок по гитарному исполнительству и композиции определено содержанием ряда исследований, из которых, начиная с докторской диссертации Фан Дин Тана [12] и кончая магистерскими, кандидатскими диссертациями Сан Юаня, Е. Мошака [8; 12], заложена систематика теории гитарного искусства в музыкальной науке. Кроме того, исследования инструментальной сферы лютневой группы, к которой принадлежит и гитара, особенно что касается мандолины-домры, которые в украинской и итальянской, отчасти в российской традиции, а также 
в ирландском роке и других областях творчества осознавались в ансамблевом единстве с гитарой, также весьма существенны в развитии музыковедческого освоения композиционно-исполнительской специфики гитарных разработок в науке о музыке.

Цель исследования - выделить органику гитарного академического существа в контексте бидермайера, определившего исторически классику гитарного обнаружения в профессиональной музыке.

Отсюда - конкретные задачи исследования: 1) обозначить особенности художественной методологии бидермайера, выделившего гитару в качестве одного из ведущих инструментов в профессиональной сфере; 2) проанализировать сочинение Grande Ouverture op.61 Мауро Джулиани в связи с установками итальянского бидермайера, обладавшего яркой спецификой, отличной от немецкого варианта данного направления.

Методологической основой работы является интонационный подход в музыковедении школы Б. Асафьева [2] в Украине [6; 9; 8, др.], с выделением в нем герменевтического, стилево-компаративного и культурологического методов.

Объект исследования - гитарное искусство бидермайера, предмет - сочинение М. Джулиани ор. 61.

Научная новизна - впервые в Украине гитарное наследие М. Джулиани стало в центре исследовательской проблематики стиля итальянского бидермайера.

Практическая ценность работы - пополнение материалов спецкласса гитары, а также курсов истории музыки и истории исполнительства в специальной средней и высшей музыкальной школе.

Бидермайер как искусство, культивировавшее «великое в малом» [9, 145-176], поднимавшее на высоту идеального служения домашнее музицирование, характеризовался значимостью раннехристианских и готических принципов мышления и творчества (см. Оксфордское движение по утверждению православия в мировом масштабе $[11,90-96])$.

Это доверие к одухотворенной «домашности» породило культуру «легких» фортепиано и богатство гитарного исполнительства и композиции. Не забываем, что великий Н. Паганини славился также гитарной игрой - расцвет гитарного искусства охватил первую половину XIX столетия, совпадая с культурно-политическим настроем Реставрации. Формально это 1813-1848 гг., а по существу она утверждалась от начала XIX века: сама идея коронации Наполеона, осущест- 
вленная в 1804 году и подготовленная событиями предшествующих ей годов, свидетельствовала о контрреволюционной направленности культуры и политики. И до недавнего времени в прогрессистски ориентированной исторической науке данное положение осознавалось как нечто негативное и компрометирующее контрреволюционным настроем выражения.

В специальной литературе обращено внимание на недооценку вклада Дж. Россини и его итальянских современников в художественные накопления мира, поскольку с конца XX столетия наблюдается «ренессанс Россини» [14, 79-90], когда на сценах театров мира стали появляться «реставрационные-контрреволюционные» сочинения типа «Путешествия в Реймс» великого композитора, написанные во славу восстановления попранной революцией Французской монархии. Снятым стало табу и с салонной активности Россини как превосходного пианиста - в амплуа игры на «легких» фортепиано, идея которых заложена была его соотечественником М. Клементи, воспитавшим великого Дж. Фильда, англичанина по гражданству, ирландца по национальности и москвича по месту жительства.

Значимость гитары была поддержана политическими установками указанного исторического периода, поскольку игра на гитаре как атрибут испанской рыцарской традиции оказалась в центре внимания в антинаполеоновской борьбе, ибо только в России и Испании сопротивление нашествию Наполеона приняло характер народной войны неприятия его политической миссии.

Юг Италии, историческими судьбами определенный бытием под испанской короной во славу итальянской музыки (чего только стоят блистательные судьбы К. Фаринелли, Л. Боккерини, др.!), определился в народных традициях ансамблевой игры на мандолинах и гитарах. Это имело свои параллели в бытовом музицировании в Украине, где ансамбль гитары и мандолины уживался с балалайкой (см. воспоминания В. П. Повзуна $[10,49])$ : «В селе, близ старой польской границы на Подолье, у меня, шестилетнего, было трио: мандолина, балалайка, гитара. Я им заправлял. Играли под немое кино... Звали нас... на свадьбы на утеху...»

Творчество замечательного итальянского гитариста, исполнителя, педагога и композитора Мауро Джулиани, оцененного Л. Бетховеном, сложилось на волне антинаполеоновской эпопеи, определив биографию и творческую позицию его сына Михаила Джулиани [3; 4]. Последний наследовал гитарную квалификацию отца, но также 
стал известен как певец и композитор, жил с 1820-х годов в России, способствуя расцвету гитарного искусства в этой стране. Однако преподавание в Парижской консерватории для М. Джулиани сложилось от 1850 года и в функции вокалиста - знаменуя отмежевание после 1848 от художественно-исполнительской эмблематики бидермайера: игры на «легких» фортепиано и гитарной художественной экспансии.

Биография Джулиани-младшего освидетельствовала отодвижение гитарного искусства как спутника бидемайера и Реставрации вплоть до вышеупомянутых событий поставангардной волны конца $\mathrm{XX}$ годов, возродившей ценности искусства первой половины XIX столетия. Тенденции утверждения гитары как соперницы скрипки прослеживаются по творческому росту М. Джулиани, изначально обучавшегося на скрипке, флейте (заметим, эти два инструмента соотносились в практике итальянской музыки, поскольку оба считались моделью вокала сопрано) и гитаре, но впоследствии отказавшегося от первых двух квалификаций в пользу гитарного искусства. М. Джулиани знаменит стал к 20 годам, получил лестное имя первого гитариста Италии и Вены. При этом неоднократно в описаниях общения с ним подчеркивалась его всесторонняя образованность, делавшая его, подобно Ф. Шопену, желанным в кругах изысканной аристократии [3].

Сочинения Джулиани для гитары призваны были утвердить высокие виртуозные достоинства данного инструмента посредством оркестрализации его выразительности - таковым был и путь других академических и академизировавшихся инструментов. В центр его композиторского наследия выдвигают четыре Концерта для гитары и оркестра, которые сравнивают с Концертами для скрипки Н. Паганини, для фортепиано Ф. Листа, в которых партии соло принципиально оснащались приемами, соперничающими по универсальности выражения с возможностями оркестра.

В России выступления М. Джулиани, представлявшего классику шестиструнной гитары, оттеснялись влиянием А. Сихры, создавшего классику же русской семиструнной гитары. И в этом же направлении сложилась деятельность Н. Макарова, организовавшего в Брюсселе в 1840-е годы международный конкурс гитаристов. В связи со сказанным ясно, что современники особо ценили сочинения Джулиани, которые демонстрировали академические достоинства гитарной игры, возвышавшие этот инструмент над бытовым уровнем его употребления (как аккомпанирующего пению). И к числу таких произ- 
ведений, несомненно, относится Grande Ouverture op.61, написанная незадолго до поездки в Россию 1822-1823 гг.

Сочинение представляет собой сложную одночастную композицию, предвосхищающую поэмные сочинения Ф. Листа, но одновременно соотносимую с раннеромантическим - бидермайеровским типом циклизации «вальсовых венков», «песенных венков», в которых доминирует не «сжатие симфонического-сонатного цикла», но монологизированное произнесение вариаций-сюит, явно произраставших из клавирности инструментализма рококо. Данная ссылка определяется спецификой итальянского и французского бидермайера, который, в отличие от бюргерского-мещанского («демократического») основания в немецкой культуре, тяготел к аристократической салонности, непосредственно наследовавшей клавирные собрания рококо XVII-XVIII столетий.

Биографические сведения Джулиани всячески акцентируют его вхожесть в высокие аристократические собрания, в том числе при дворе австрийского императора, хотя аристократия не имела тогда столь высокого социального статуса, каковой выделял участников французского салона эпохи короля-солнца. Петербург и Москва в России представляли близкую традицию к французско-итальянской разновидности салонного бидермайера, так же как «шляхетский» (и часто совершенно поместный) бидермайер отличал польский и украинский варианты этого рода культурной традиции. Лучшее тому свидетельство - проживание в Москве великого ученика «лондонца» М. Клементи - Дж. Фильда, концентрировавшего в своем искусстве «жемчужной-бриллиантовой» игры специфику салонного бидермайера первой трети XIX века.

Grande Ouverture op.61 М. Джулиани представляет собой вариационно-сюитный цикл, в котором намечены соотношения поэмной композиции, но лишенной сонатной антитетичности составляющих ее частей. Показательно симфоническое наименование произведения, соответствующее технике оркестрализации-театрализации изложения сольного звучания гитары. Соответственно сочинение отмечено максимальным разнообразием фактурных обнаружений гитарной игры, в том числе богатством сопоставлений аккордово-многоголосных и мелодически выраженных структур, пассажных последовательностей.

Общий план Grande Ouverture указывает на ориентировку на тип французской увертюры, поскольку открывается композиция 
медленным в маршевом движении вступлением (Andante maestoso, a-moll), после чего следует основной раздел Allegro maestoso, A-dur. Соотношение указанных частей - принципиально неравнозначно: Andante maestoso - тт. 1-15, тогда как Allegro maestoso - тт. 16-217. Как видим, общим выразительным показателем медленной и быстрой частей композиции является их маэстозность, то есть нарочитая торжественность изложения, сообщающая возвышающую внушительность подачи всех тем сочинения.

Первая тема-образ, в музыке Andante maestoso, содержит подчеркнутые патетические обороты, в том числе это в т. 2 ход на уменьшенную септиму, составляющий знаменитую знаковую риторическую фигуру напряжения-страдания. В первой медленной части Большой увертюры показан еще один значимый оборот: восходящая фигура anabasis, отражающая представление о душе, устремленной к небу, но данная в виде хроматического хода, passus duriesculus, то есть в некотором омрачении напряженного подъема-усилия (см. тт. 5-8: $\left.\mathrm{c}^{2}-\mathrm{cis}^{2}-\mathrm{d}^{2}-\mathrm{dis}^{2}-\mathrm{e}^{2}\right)$. В целом начальный образ выделен динамическими и фактурными сопоставлениями - в духе диалогичности «двух принципов» [7, 295] Л. Бетховена (который, напоминаем, чрезвычайно одобрительно отнесся к М. Джулиани, в том числе написав ряд произведений для гитары с расчетом на исполнение Маэстро).

Allegro maestoso, A-dur выделено ладовым контрастом, подкрепленным динамическими показателями: нежная звучность на piano, в духе «моцартовых интонаций» с хроматическими неприготовленными задержаниями на сильном времени, - все это противостоит динамически-фактурным сопоставлениям Andante maestoso. И все же имеется связующая нить медленного вступления и Allegro: последнее также открывается хроматическими «расцвечиваниями» пентахордной последовательности fis ${ }^{2}-\mathrm{e}^{2}-\mathrm{d}^{2}-\mathrm{cis}^{2}-\mathrm{h}^{1}$, выделенной неприготовленными задержаниями с альтерированными звуками.

Начальный ход этой первой темы Allegro maestoso составляет отклонение в Fis, в тональность VI высокой ступени A-dur. Далее осуществляются вводные построения к соответствующим указанным ступеням пентахорда, что позволяет обнаружить тоническую гармонию не в начальных тактах раздела. Данная тема излагается в аккордовых последовательностях, которые отличают ее от других тем сочинения. Патетический смысл изложения поддержан речитативом тт. 21-22.

Фактурный контраст вводит вторую тему Allegro maestoso (т. 23), антитеза которого смягчена показом в исходной тональности: имен- 
но эта вторая тема демонстрирует тоничность в изложении вертикали, поскольку выдержана на бурдоном базисе, вносящем контрастно-полифонический принцип в изложение Увертюры.

Следующий этап - развивающие структуры, вводящие пассажную-токкатную звучность в гитарную музыку, что составляет новый этап музыкального движения. Это отмечено показом сначала E-dur (т.39), затем C-dur (т.40-43), а затем H-dur (т. 43); создается цепь мажорных аккордов, создающих эффект «дважды мажора» целотонного лада, составляющего исключительный поворот ладово-гармонической динамики композиции. Устанавливается стойкая дробность ритмического движения, в русле которого (от т. 53) обнаруживается фактура выраженного диалога - неравно представленного активным мелодизмом верхнего голоса и комплиментарными «репликами» нижнего.

Названные «экстремальные» ладово-гармонические и фактурные приемы уготавливают центральный раздел Увертюры - в C-dur (от т. 87). Последний выделяется явными quasi-opкестровыми diminuendo, создающими особого рода «динамическую вибрацию», образующую специфику данного этапа композиции. В его проявление включены демонстративные ладовые отклонения, поскольку в тт. 99-102 выделяются арпеджированные ходы по звукам аккордов c VI низкой. Далее выделено отклонение в d-moll, изобильно представленное в фактуре с подчеркнутым многоголосным изложением. Фактурный принцип этого раздела в C-dur может быть определен как «романс без слов»: очевидна гомофонно-гармоническая раскладка голосов и модели речево-просительных оборотов в мелодическом контуре.

В конце концов, вновь устанавливается звучание C-dur'a, после чего, от т. 122 обнаруживается реприза (возвращается A-dur). Репризные проведения достаточно полно воспроизводят этапы показа первой и второй тем (это все в A-dur), а также развивающих фрагментов, что в совокупности охватывает более 60 тактов музыки. Следует отметить признаки динамизации репризных построений: от т. 151 выделяется диалогизированное изложение в обновленном фактурном проявлении по сравнению с экспозиционным его показом (от т. 53).

Этап коды обозначен специальным отклонением в F-dur (т. 189) а также динамическим «падением» на уровень pianissimo. Фактура напоминает романсовую монологичность раздела в C-dur, но с другим контурно-мелодическим наполнением: молитвенное псалмоди- 
рование и «всплески» интервальных «бросков» привносят особого рода душевную тонкость в выражении. В целом же соотнесенность указанных разделов, в C-dur и в F-dur, придает форме так называемые дополнительные сонатные отношения, ибо указанные фрагменты «романса без слов» претендуют на функцию побочной партии в тематических сопоставлениях.

Обнаружения от т. 193 стойкой устремленности в основной A-dur совмещены с подчеркиванием хроматики, настойчиво показанной в начальных экспозиционных и репризных демонстрациях тем (см. хроматически восходящую линию в верхнем голосе $\mathrm{c}^{2}-\mathrm{cis}^{2}-\mathrm{d}^{2}-\mathrm{dis}^{2}-$ $\mathrm{e}^{2}$ ). Эти хроматически выдаваемые признаки напряжения порождают клавирно-оркестральное изложение по фактуре завершающих тактов произведения, демонстрирующего высшую в композиционном охвате динамическую шкалу, демонстративные «перебросы» аккордов по регистрам, что в совокупности заявляет эти завершающие такты кульминирующим построением Увертюры.

Так изложение Grande Ouverture М. Джулиани выводит как бы на эпическую двукульминационную структуру, из которых первая - дана во вступлении, а вторая, значительно превышающая уровень первой, - в завершающем построении Увертюры. Запечатлеваем это в следующей архитектонической схеме:

And.maestoso A 11 e g r o m a e s t o s o

A B C D E B C D E ${ }^{1}$

a-moll A-dur C-dur A-dur F/A-dur

\section{II}

Как запечатлено на данной схеме, общий план строения напоминает поэмную двухфазность, установившуюся к началу XX века и в полноте проявивщуюся в «Вальсе» М. Равеля. Эти уподобления манеры письма протосимволизма начала XIX и символизма начала XX столетия закономерны как предшествование и реализация стилистической идеи неосимволизма как стилистического уточнения выразительного принципа искусства поставангарда.

В исполнении выдающихся гитаристов Дмитрия Илларионова (Россия) и Мануэля Эспиназа (Espinás, Испания) представлены как бы полярности стилевого слышания сочинения Джулиани. Илларионов явно представляет (и блестяще!) традиционную театральность в исполнении, не без импрессионистско-символистских «касаний»: 
богатая палитра динамики, демонстративные темповые контрасты, очевидная «оркестрализация» гитарной звучности.

Испанский гитарист М. Эспинас гораздо более «ровен», звучит как бы проще - без демонстративных динамических и темповых перепадов, что приближает его к салонной традиции. Этому противоречит умеренный темповый принцип, поскольку салонная игра всегда подчинялась изящной «полетности» (и совершенно не-театральной) пассажности. Но салонность - это признак французской-итальянской разновидности бидермайера, тогда как «базовый» вариант этого направления - немецкий бидермайер - демонстрировал более сдержанный темповый тонус в соответствии с установкой на «песни-романсы без слов». Последний, судя по всему, привлек внимание испанского исполнителя.

Выводы. Сказанное позволяет осознать высокие достоинства «Большой увертюры» М. Джулиани в представительстве классики гитарного искусства итальянского бидермайера. Последнее в условиях современного постмодерна обнаруживает противонаправленные тенденции проромантической театрализации-оркестрализации звучания инструмента-соло и пробидермайеровского салонного символизма, что закономерно вписывается в полиметодологические раскладки творчества сегодняшнего дня.

\section{СПИСОК ЛИТЕРАТУРЫ}

1. Андросова Д. Символизм и поликлавирность в фортепианном исполнительстве XX в. Одесса: Астропринт, 2014. 400 с.

2. Асафьев Б. Музыкальная форма как процесс. Москва; Ленинград: Музыка, 1971. 379 с.

3. Джулиани (Giuliani) Мауро. Музыкальная энциклопедия: в 6 томах / гл. ред. Ю. Келдыш. Т. 2: ГОНДОЛЬЕРА-КОРСОВ. Москва: Сов.энциклопедия, 1974. С.228.

4. История гитары в лицах. URL: www.abc-guilas.com - guiter-times.ru

5. Кассу Ж. Энциклопедия символизма: Живопись, графика и скульптура. Литература. Музыка / науч.ред и авт. послесл. В. М. Толмачев; пер. с фр. М.: Республика, 1999. 412 с.

6. Маркова Е. Проблемы музыкальной культурологии. Одесса: Астропринт, 2012. $164 \mathrm{c}$.

7. Маркус С. История музыкальной эстетики: в 2 томах. М.: Музгиз, 1959. T.1. $316 \mathrm{c}$.

8. Мошак $€$. Традиції гітарної музики в контексті європейської музичної культури другої половини XX століття: автореф. дис. ... канд. мистецтвознавства: 17.00.03 / ОНМА імені А. В. Нежданової. Одеса, 2012. 16 с. 
9. Муравська О. Нариси з історії зарубіжної музичної культури. Вип.1. Одеса: Друкарський дім, 2010. 214 с.

10. Одесская консерватория: славные имена, новые страницы / гл. редактор Н. Огренич; ред.-сост. Е. Маркова. Одесса: Астропринт, 1998. 333 с.

11. Русская Православная Церковь 988-1988. Очерки истории I-XIX вв. Вып. 1. Москва: Изд. Москов. Патриархии, 1988. 112 с.

12. Сан Юань. Жанр элегии в художественной традиции и в музыке Й. Мерца: магистерская работа: 17.00.03 / ОНМА имени А. В. Неждановой. Одесса, 2006. 49 с.

13. Фан Динь Тан. Проблема «Восток - Запад» и дальневосточная художественная культура. К.: Национальная музыкальная академия Украины им. П. И. Чайковского, 1998. 310 с.

14. Grempler M. Rossini e la patria. Kassel: G. Bosse Verlag, 1996. 241 s.

\section{REFERENCES}

1. Androsova, D. (2014). Symbolism and poliklavirnost in pianistic performance of the twentieth century. Odessa: Astroprint [in Russian].

2. Asafiev, B (1971). Musical form as a process. Moscow-Leningrad: Music [in Russian].

3. Giuliani Mauro (1974). The musical encyclopedia in 6 volumes.. Vol. 2 Gondolier-Cors. Moscow: Soviet Encyclopedia., Vol. 2 P.228. [in Russian].

4. History of the guitar in the faces. URL: www.abc-guilas.com - guiter-times.ru

5.Cassu, J (1999). Encyclopedia of Symbolism: Painting, graphics and sculpture. Literature. Music. M.: Republic [in Russian].

6.Markova, E (2012). Problems of musical culturology. Odessa: Astroprint [in Russian]. 7.Markus, S (1959). History of musical aesthetics in 2 volumes. M.: Muzgiz, Vol.1 [in Russian].

8.Moshak, E (2012). Traditions of guitar music in the context of European musical culture of the second half of the twentieth century. Extended abstract of candidate's thesis. Odessa: [in Ukrainian].

9. Muravskaya, O (2010). Essays on the history of foreign musical culture. Issue 1 Odessa: Printing House, [in Ukrainian].

10. Odessa Conservatory: nice names, new pages (1998). / Ch. Editor N. N. Ogrenich, Odessa: Astroprint [in Russian].

11. The Russian Orthodox Church 988-1988. Essays on the history of the I-XIX centuries. Issue 1. Moscow: Izd. Moscow. Patriarchy [in Russian]..

12.San Yuan (2006). Genre of elegies in the artistic tradition and music of J. Mertz. Master's work. Odessa : [in Russian].

13.Fan Dinh Tang (1998) The East-West problem and the Far Eastern art culture. K.: National Music Academy of Ukraine. P. I. Tchaikovsky [in Russian].

14.Grempler, M (1996). Rossini e la patria. Kassel: G. Bosse Verlag, [in Italian]. 